\title{
Aortic dissection with acute malperfusion syndrome: Endovascular fenestration via the funnel technique
}

\author{
Anne Vendrell, MD, ${ }^{\mathrm{a}}$ Julien Frandon, MD, ${ }^{\mathrm{a}}$ Mathieu Rodiere, MD, ${ }^{\mathrm{a}}$ Olivier Chavanon, MD, PhD, \\ Jean-Philippe Baguet, MD, PhD, ${ }^{\mathrm{c}}$ Ivan Bricault, MD, PhD, ${ }^{\mathrm{a}}$ Bastien Boussat, MD, ${ }^{\mathrm{d}}$ \\ Gilbert Raymond Ferretti, MD, $\mathrm{PhD},{ }^{\mathrm{a}}$ and Frédéric Thony, $\mathrm{MD}^{\mathrm{a}}$
}

\begin{abstract}
Objective: To analyze the short- and long-term results of an original aortic fenestration method using the funnel technique during aortic dissection complicated by malperfusion syndrome.

Methods: The funnel technique consists of deployment of an uncovered aortic stent graft placed from the false to the right lumen through an intimal flap aortic fenestration made by balloon angioplasty. Twenty-eight patients presenting with an aortic dissection (type $\mathrm{A}, \mathrm{n}=19$; type $\mathrm{B}, \mathrm{n}=9$ ) were treated for malperfusion syndrome owing to dynamic compression (16 renal, 17 bowel, and 13 lower limb ischemia) using the aforementioned technique, and had follow-up evaluation at short term (30 days) and long term (mean: $55 \pm 40$ months). Eight patients had severe ischemia on arrival (6 bowel, 7 renal, 3 lower limb).
\end{abstract}

Results: Technical success was achieved in 27 of 28 patients (96\%), and ischemic symptoms had disappeared in 25 of 28 patients $(89 \%)$ at short-term follow up. Five patients presented postprocedure complications: 4 minor and 1 major with arterial thrombosis which caused technical failure (3.6\%). The 30-day mortality rate was $7 \%(\mathrm{n}=2)$, related to bowel ischemia complications. At long-term follow up, 21 patients had a stable thoracic aortic diameter (91\%).

Conclusions: The funnel technique, in cases of malperfusion syndrome after aortic dissection, safely improves short- and long-term clinical outcome, and could represent an interesting alternative in the management of patients. The hemodynamic efficiency of this technique may account for a lower mortality in our series. (J Thorac Cardiovasc Surg 2015;150:108-15)

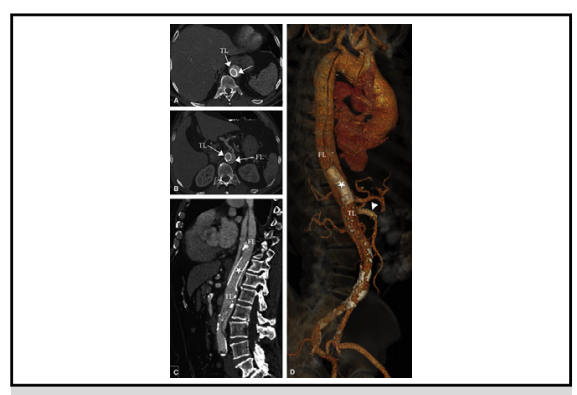

The funnel technique: An uncovered aortic stent graft is used between the false and the true lumen.

\section{Central Message}

The funnel technique is a novel aortic fenestration method (clinical success rate here: $89 \%$ ), using a stent graft through the intimal flap, for patients with malperfusion syndrome.

\section{Perspective}

The funnel technique, versus other techniques to treat malperfusion syndrome during aortic dissection, has better efficacy and a lower rate of morbidity. As an alternative to covering the primary entry tear, when this is unfeasible, it protects against short-term ischemic recurrence. Long term, it permits a decrease in pressure in the false lumen, protecting against potential thoracic aortic dilatation, which occurs in $20 \%$ to $50 \%$ of cases.

See Editorial Commentary page 116.
Acute aortic dissection (AD) is a rare, but serious, disease ${ }^{1}$ that induces a high mortality rate $(50 \%)$ at 48 hours. ${ }^{2,3}$ The Stanford classification of $\mathrm{AD}^{4}$ differentiates type $\mathrm{A}$, which

\footnotetext{
From the ${ }^{\mathrm{a}}$ Clinique Universitaire de Radiologie et d'Imagerie Médicale, Centre Hospitalier Universitaire de Grenoble; ${ }^{\text {}}$ Clinique Universitaire de Chirurgie CardioThoracique, Centre Hospitalier Universitaire de Grenoble; ' $S e r v i c e$ de Cardiologie, Clinique des Eaux Claires, Groupe Hospitalier Mutualiste de Grenoble; and ${ }^{\mathrm{d}}$ Université Joseph Fourier, Laboratoire de Techniques de l'Ingénierie Médicale et de la Complexité - Informatique, Mathématiques et Applications, Grenoble (TIMC-IMAG), Centre Hospitalier Universitaire de Grenoble, Grenoble, France.

Received for publication Jan 8, 2015; revisions received March 18, 2015; accepted for publication March 30, 2015; available ahead of print May 1, 2015

Address for reprints: Anne Vendrell, MD, Clinique Universitaire de Radiologie et d'Imagerie Médicale (CURIM), CHU de Grenoble, BP 10217, 38043 Grenoble, Cedex 09, France (E-mail: AVendrell@chu-grenoble.fr).

$0022-5223 / \$ 36.00$

Copyright (c) 2015 by The American Association for Thoracic Surgery

http://dx.doi.org/10.1016/j.jtcvs.2015.03.056
}

requires surgical management, ${ }^{5}$ from type $\mathrm{B}$, which is treated medically. ${ }^{6}$

Malperfusion syndrome (MPS), caused by reduced flow in the aortic branch vessels, is the second most common complication (20\%-50\%) of $\mathrm{AD},{ }^{7}$ after cardiac complications, ${ }^{8}$ and causes higher mortality $(51 \%$ vs $29 \%$ in survivors of AD). ${ }^{9-11}$ Two ischemic mechanisms have been described $^{12}$ : dynamic compression due to an aortic true lumen collapse; and static compression related to direct extension of $\mathrm{AD}$ into an aortic branch.

In cases of dynamic compression MPS, closing the primary entry tear of the dissection, by using a covered stent, is the recommended treatment. ${ }^{13-16}$ When this method is unfeasible, aortic fenestration (AF) has been proposed as an alternative technique ${ }^{17-20}$; however, high postprocedural 


\section{Abbreviations and Acronyms \\ $\mathrm{AD}=$ aortic dissection \\ $\mathrm{AF}=$ aortic fenestration \\ $\mathrm{CT}=$ computed tomography \\ MPS $=$ malperfusion syndrome}

complications (11\%-20\%) and mortality rates (17\%-34\%) have been reported.

In our center, a new and original AF technique, consisting of an uncovered aortic stent graft, inserted between the false and the right lumen, was performed on selected patients. The aim of this study was to assess the safety and efficacy of this technique, known as the "funnel technique," at short- and long-term follow-up evaluation.

\section{METHODS}

\section{Study Design}

The local institutional review board (No. 5891) approved this retrospective study. Relevant and follow-up data were collected and reviewed, using the medical files and imaging exams of included patients. From January 1, 2000 to December 31, 2013, all consecutive patients admitted to our center and presenting with renal, digestive, and/or lower limb ischemia, owing to dynamic compression MPS, after type A or type B $\mathrm{AD}$, was treated with this new procedure. These patients could not be treated with a thoracic aortic stent graft, because of anatomic constraints, as they had an entry tear either in the aortic segment II or next to the supra aortic trunks.

Diagnosis of MPS was based on clinical, biologic, and/or radiologic features, according to the following criteria:

- Renal ischemia: uncontrolled arterial hypertension, defined as blood systolic pressure $>120 \mathrm{~mm} \mathrm{Hg}$, despite 2 doses of intravenous antihypertensive therapy; variation of serum creatinine $\geq 44 \mu \mathrm{mol} / \mathrm{L}$; or decreased glomerular filtration rate of $>25 \%{ }^{21}$; evidence of renal malperfusion on CT scan in nonsevere forms; anuria in severe forms.

- Lower limb ischemia: absent pulse, claudication, cool limb, low flow in the iliac arteries in nonsevere forms; sensorimotor deficit in severe forms. - Bowel ischemia: abdominal pain and diarrhea in nonsevere forms; bowel tract bleeding, high lactate levels, and/or lack of enhancement of bowel wall on CT scan in severe forms.

The preoperative CT scan additionally confirmed the dynamic compression, with the collapse of the true lumen, and the absence of concomitant disease, which could explain the symptoms. These types of ischemia and their severity are described in Table 1. Depending on the patient, MPS occurred during the dissection, postoperatively, or later. The time from diagnosis to treatment varied from 3 to 72 hours.

\section{Procedure}

A preprocedure contrast-enhanced CT scan was systematically performed, to determine the orientation of the intimal flap and the fenestration target, located $4 \mathrm{~cm}$ above the celiac trunk. All procedures were performed by 2 interventional radiologists with $>10$ years of experience, under fluoroscopic guidance. The initial anteroposterior and lateral angiography in the true lumen was first done under local anesthesia, through a femoral sheath, to confirm the dynamic compression and identify the flap orientation. In a curved $5 \mathrm{~F}$ catheter, positioned $4 \mathrm{~cm}$ above the celiac trunk facing the intima, a rigid 0.014-inch Spartacore guidewire (Abbott Vascular, Santa Clara, Calif) was introduced in the reverse position (hard end first), pushed through the flap, and advanced into the false lumen.

The fenestration opening was enlarged by using an 18-mm-diameter balloon (Boston Scientific, Natick, Mass) after changing the introducer for a $10 \mathrm{~F}$ sheath and replacing the guidewire with a 0.035 -inch guidewire (Terumo, Yamanashi, Japan). An uncovered self-expanding steel stent (Wallstent, Boston Scientific, Natick, Mass), or a nitinol stent (Memotherm, Bard Angiomed, Wachhausstrasse, Germany) of 18 to $24 \mathrm{~mm}$ in diameter and 40 to $60 \mathrm{~mm}$ long, was deployed from the false lumen toward the true lumen through the opening created, with its distal end placed above the ostium of the celiac trunk.

The final angiography was performed in the false lumen, above the fenestration, and had to confirm satisfactory flow in the true lumen (increased caliber, rapid and intense enhancement) and the aortic branches. Upstream of the stent, the true aortic lumen was expected to be collapsed by the stent (Figures 1-4). If the angiographic result was inadequate, an additional subrenal fenestration without stenting or peripheral stenting of side branches was discussed. For the following 6 months, patients received an antiplatelet treatment, except those treated with oral anticoagulants.

\section{Definitions}

Technical success was defined as a normal blood flow velocity in the stent, the true lumen, and the aortic branches, with a normal perfusion of end-organs on the final angiogram, in either a single procedure (primary technical success) or 2 procedures, whether or not simultaneous (secondary technical success). Clinical success was defined as clinical symptoms having disappeared, and biologic parameters having normalized between day +1 and day +30 . The main evaluation criterion was clinical success. The secondary evaluation criteria were mortality and complication rate in the short term (between day +1 and day +30 ); and onset of late complications and evolution of thoracic aorta diameter in the long term.

Patients were followed up, with magnetic resonance imaging or CT, at day $+10 ; 6$ months; 12 months; and every 2 years thereafter. The mean duration of the follow-up period was defined as the time between the initial imaging study and the last available images. The thoracic aorta was measured on the same levels in the axial plane. Increased aortic diameter was defined as a diameter $>60 \mathrm{~mm}$, or progressing $>4 \mathrm{~mm} /$ year. Data were summarized using the mean and the median $(25 \%-75 \%$ interquartile range). The Kaplan-Meier technique was used to create a survival curve. Growth rates for aortic diameter were estimated with linear regression, using a linear, mixed-effects model. Linear, mixed-effect regression analysis was carried out, using follow-up time, the localization of the primary entry tear, the involvement of the ascending aorta, age, and pre-existing hypertension.

\section{RESULTS \\ Population}

Within 13 years, 379 patients were admitted to our center for $\mathrm{AD}$ (type $\mathrm{A}, \mathrm{n}=259$; type $\mathrm{B}, \mathrm{n}=120$ ). Among patients presenting with type A, 247 of 259 (95.4\%) underwent surgical aortic replacement, and 12 of $259(4.6 \%)$ died before the surgery. All patients with type B AD were treated medically. Sixty-nine of 379 patients $(18.2 \%)$ presented dynamic compression MPS, and were treated with either thoracic endovascular aortic repair $(n=41)$ or AF, by the funnel technique $(\mathrm{n}=28)$.

Of the 28 treated by the funnel technique, 19 patients presented type $\mathrm{A}$ AD and underwent emergency cardiac 
TABLE 1. Various types of ischemia, and their severity

\begin{tabular}{|c|c|c|c|c|}
\hline \multirow[b]{2}{*}{ Ischemia areas } & \multicolumn{3}{|c|}{ Definition } & \multirow[b]{2}{*}{$\mathbf{n}$} \\
\hline & Clinical & Biologic & Radiologic & \\
\hline \multicolumn{5}{|l|}{ Renal ischemia } \\
\hline Nonsevere & Uncontrolled arterial hypertension & $\begin{array}{l}\text { Variation of serum creatinine } \geq 44 \mu \mathrm{mol} / \mathrm{L} \text { or } \\
\quad \text { decreased glomerular filtration rate }>25 \%\end{array}$ & Renal malperfusion & 9 \\
\hline Severe & Anuria & & & 7 \\
\hline \multicolumn{5}{|l|}{ Bowel ischemia } \\
\hline Nonsevere & Abdominal pain, diarrhea & & & 11 \\
\hline Severe & Bowel tract bleeding & High lactate levels & $\begin{array}{l}\text { Lack of enhancement of } \\
\text { bowel wall }\end{array}$ & 6 \\
\hline \multicolumn{5}{|l|}{ Lower-limb ischemia } \\
\hline Nonsevere & Absent pulse, claudication, cool limb & & Low flow in iliac arteries & 10 \\
\hline Severe & Sensorimotor deficit & & & 3 \\
\hline
\end{tabular}

surgery (14 aorto-aortic tubes, 4 Bentall procedures, and 1 hemiarch replacement), always performed first, regardless of the severity of MPS. Nine patients presented type B AD. Patient characteristics and ischemic areas are summarized in Table 2. Eight of 28 patients $(29 \%)$ presented severe ischemia: mesenteric $(n=6)$, renal $(n=7)$, or lower limb $(n=3)$. Additional stenting for concomitant static compression was necessary in 13 of 28 patients: renal $(n=7)$, superior mesenteric $(n=5)$, and iliac $(n=5)$.

\section{Recanalization}

Primary technical success was $86 \%$ (24 of 28 ), and secondary technical success was $96 \%$ (27 of 28 ), with no intraprocedural complications. Three patients required a
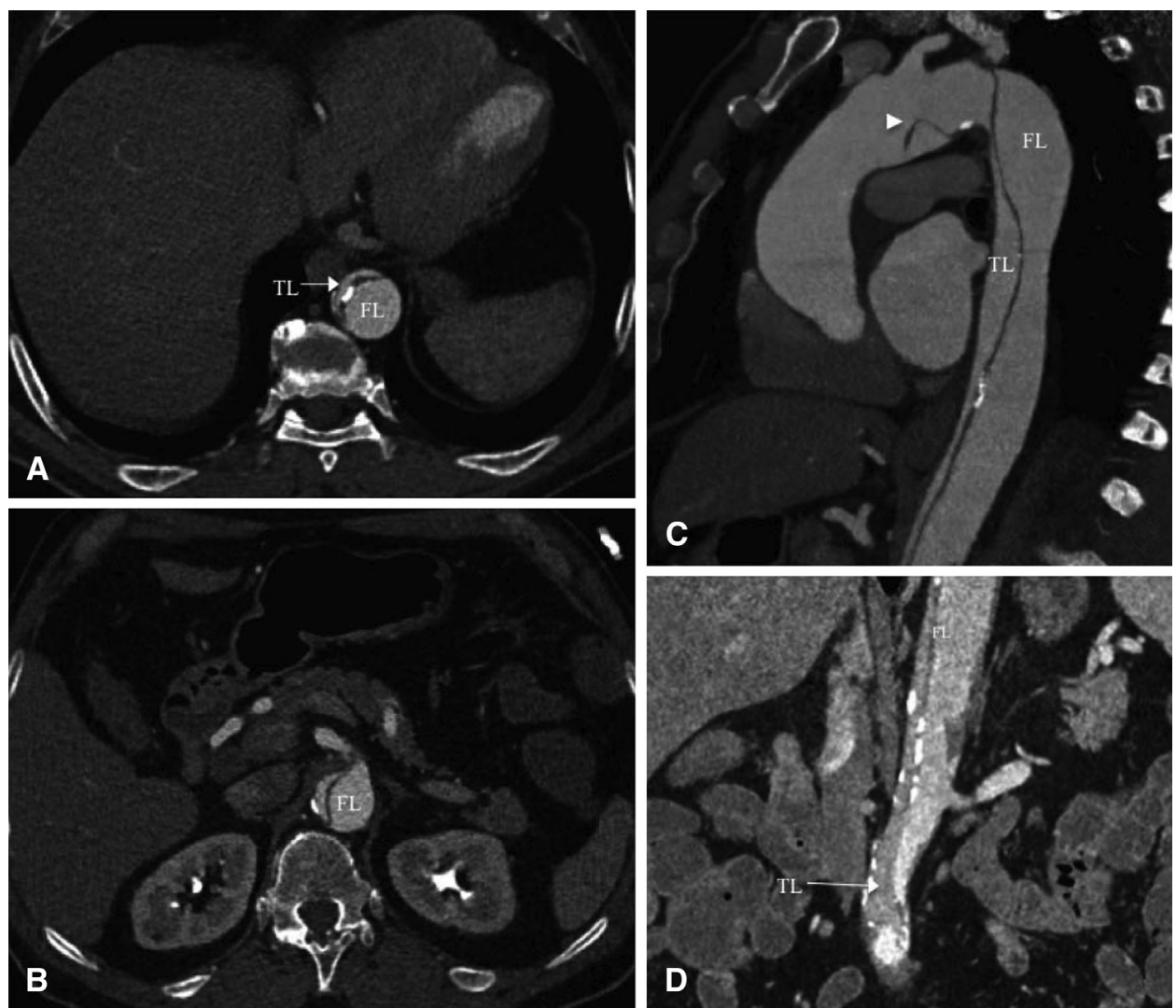

FIGURE 1. A 71-year-old patient admitted for acute type B aortic dissection, with severe bowel ischemia (bowel tract bleeding and high lactate level) due to dynamic compression and dissection of the superior mesenteric artery. A and B, Angio CT scan on axial views, (C) sagittal and (D) coronal reformations, showing thoraco-abdominal type $\mathrm{B} \mathrm{AD}$, with a large primary entry tear located in the aortic arch (arrowhead); compression of the TL by the FL in the abdominal aorta, decreasing blood flow in the abdominal arteries. $T L$, True lumen; $F L$, false lumen. 


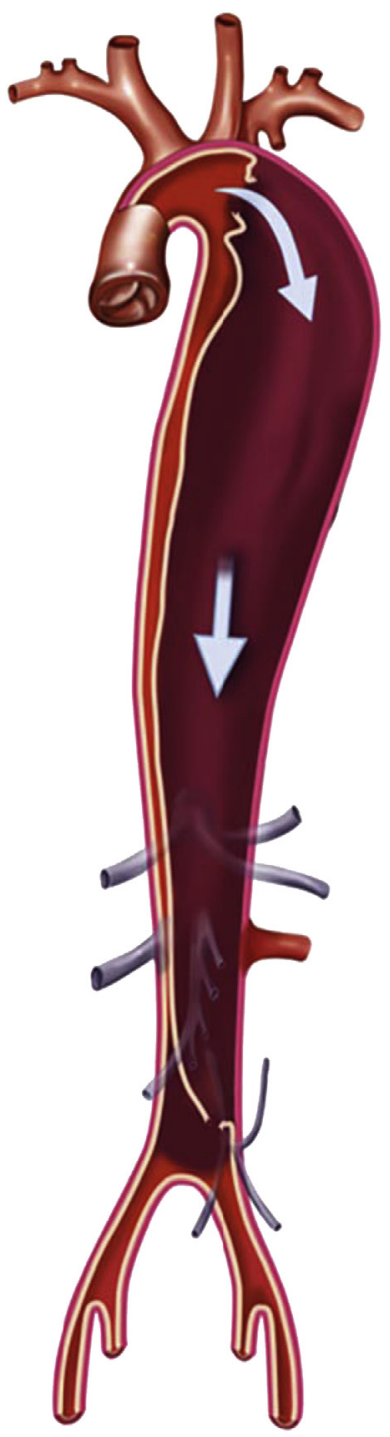

A

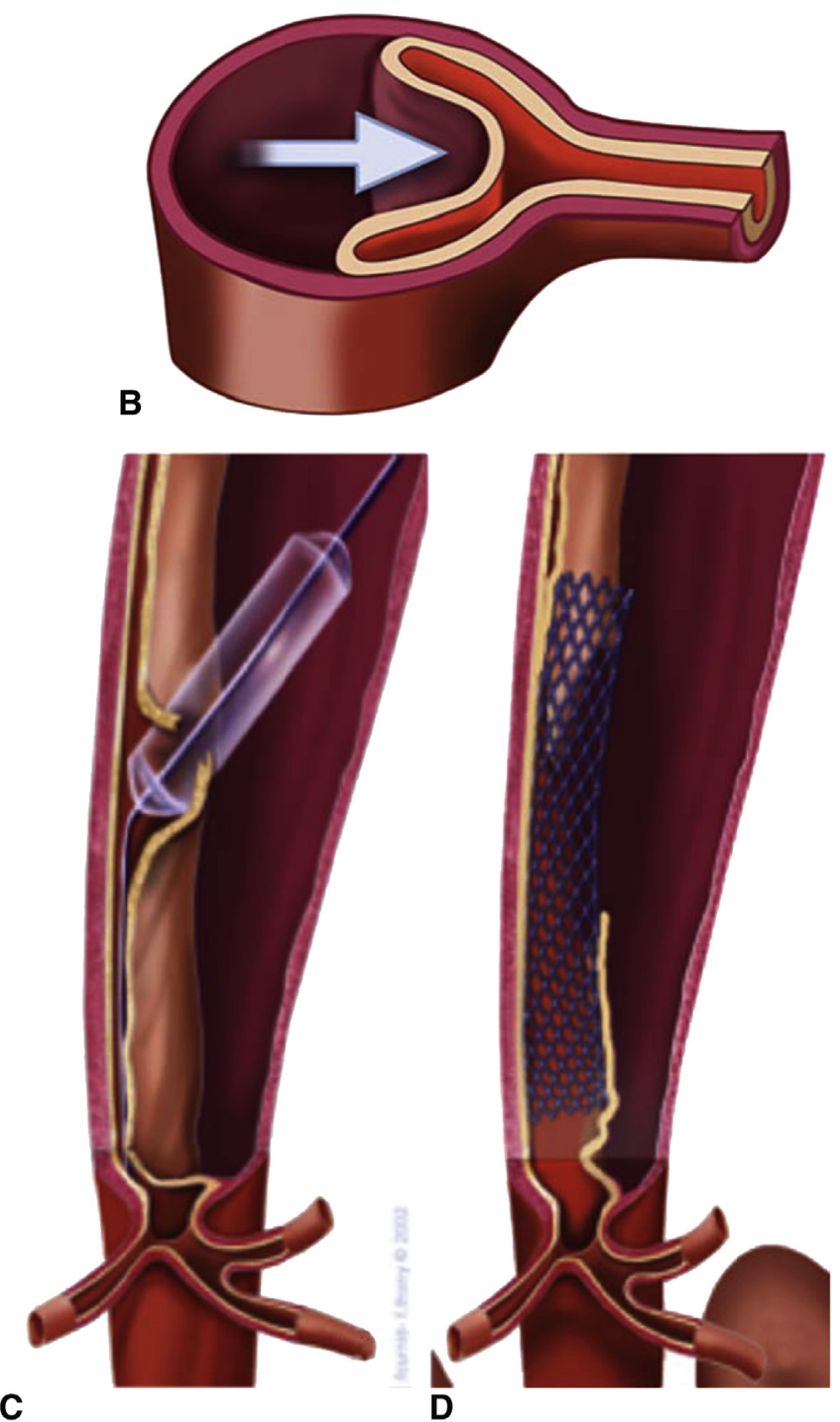

FIGURE 2. Illustration of the funnel technique: $\mathrm{A}$ and $\mathrm{B}$, shows the dynamic compression. The true lumen is collapsed by the large false lumen. $\mathrm{C}$ and $\mathrm{D}$, Aortic fenestration with balloon angioplasty of the fenestration opening and deployment of the stent graft across the false and the true lumen.

second subrenal AF: 1 during the same procedure, because of insufficient flow in the iliac arteries on the final angiogram; and 2 patients at day 2 and day 15, respectively, because of recurrence of their ischemic symptoms. Clinical success was achieved in 25 of 28 patients $(89 \%)$. Two patients $(7 \%)$ with severe ischemia (1 renal and bowel ischemia, 1 at all 3 sites), treated with cardiac surgery and then AF at day 0, died before day 30: The first on day 2, of multisystem organ failure; the second of septic shock, on day 14.

One patient was considered a technical and clinical failure, and had major complications because of worsening of a right lower-limb ischemia, at the end of the procedure, related to the onset of a thrombosis of the common femoral artery on the sheath. The patient was treated with embolectomy and femoro-femoral bypass, resulting in good postoperative evolution.

\section{Severe Ischemia}

Six of 8 patients with severe ischemia survived. Of the 4 survivors with mesenteric ischemia, all patients evolved favorably, 3 of whom required bowel resection. Dialysis was reversible after $\mathrm{AF}$, for the 5 patients with severe renal ischemia. Of the 2 patients with severe lower-limb ischemia, both improved after fenestration, although 1 required a femoral bypass, as previously described. Table 3 summarizes the characteristics of the patients with severe ischemia. 

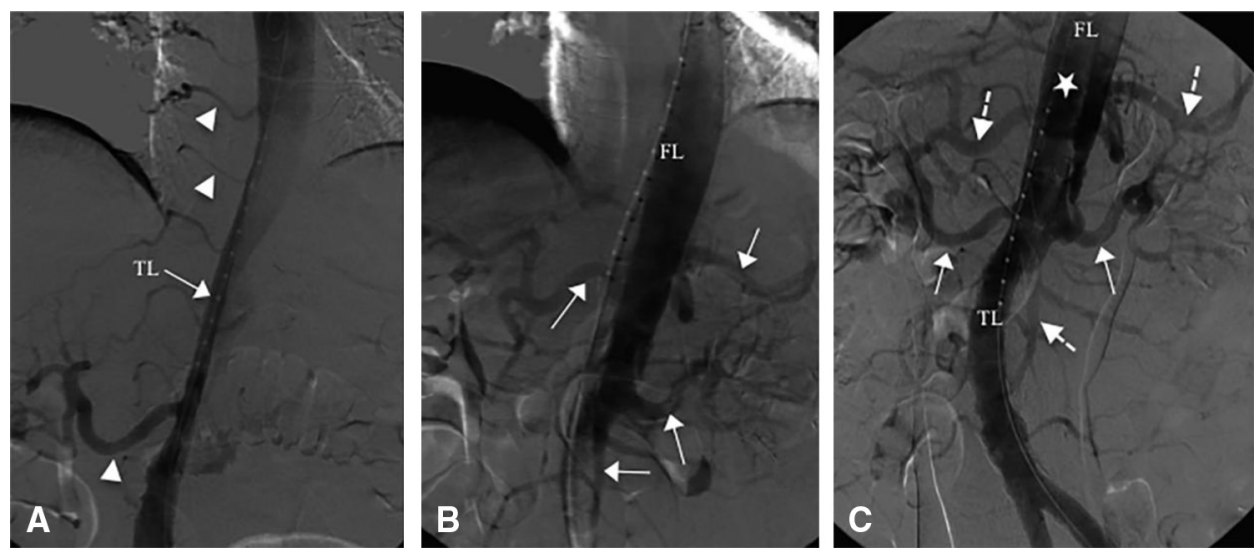

FIGURE 3. Aortic fenestration using the funnel technique in the same patient. A, Angiogram showing a collapsed TL. The right renal artery and the intercostal arteries originate from the TL (arrowheads). B, Angiogram of the FL after insertion of a catheter through the intimal perforation, showing the celiac trunk, the left renal artery, and the superior and inferior mesenteric arteries (white arrows). Only the first part of the superior mesenteric artery is supplied by the FL. C, Final angiogram with injection in the FL. The blood flow in the TL has been restored by the stent graft (star) with good patency of both renal arteries (solid arrows), the celiac trunk (splenic and hepatic arteries), and the superior mesenteric artery (dashed arrows). TL, True lumen; $F L$, false lumen.

\section{Complications}

Five patients presented complications. The major complication was described earlier. Of the 4 minor complications, 3 were related to the puncture point (arterial thrombosis resolved with medical treatment; hematoma and infection resolved with antibiotics). The last complication was an aortic stent fracture on a nitinol stent, discovered on the follow-up CT at day 10, with no clinical or biologic repercussions, and was treated by placing a second stent within the fractured one.

\section{Follow-up Evaluation}

During the follow-up period, 3 patients were lost to follow up after hospitalization, and 3 had died (Figure 5): 2 at 1 year of follow up, the first after surgical replacement of the descending aorta, and the second of a brain tumor; the third of fissuration of a descending thoracic aortic aneurysm at 9 years of follow up. Of the 23 patients who were followed up, 1 proximal fracture of a nitinol stent was detected on the 2-year follow-up CT, with no consequences. No recurrence of ischemia was observed.

Aortic diameter increased significantly over time $(P=.0038)$ at a mean rate of $1.46 \mathrm{~mm} /$ year. Two patients had a significantly increased aortic thoracic diameter $(9 \%)$ and needed surgical treatment. No risk factors among the localization of entry tear, the involvement of the ascending aorta, age, or pre-existing hypertension were identified.

Of the 41 patients treated by thoracic endovascular aortic repair (type $B, n=34$; type $A, n=7$ ), 6 patients died, and 3 presented endoleaks with recirculation of the false lumen (type II, $\mathrm{n}=2$; type $\mathrm{I}, \mathrm{n}=1$ ). These patients were treated by an embolization of the endoleaks and had a good clinical outcome.

\section{DISCUSSION}

The current recommended treatment for MPS caused by dynamic compression is to close the primary entry tear of the $\mathrm{AD}$ with a covered thoracic stent graft. ${ }^{14,16,22,23}$ However, when such treatment is not possible, AF can resupply the true lumen at the abdominal level, by creating communication between the 2 lumens. Two techniques of $\mathrm{AF}$ have been described: fenestration with balloon angioplasty, ${ }^{19,20,24,25}$ and the scissor technique. ${ }^{26}$ These series were done in 34 patients ${ }^{17}$ and 40 patients, ${ }^{20}$ respectively. Our technique is new and original because it enlarges the surface area of the re-entry orifice in the true lumen with an endoaortic stent positioned between the 2 lumens, which increases flow and pressure in the true lumen and reduces them in the false lumen, thus improving the efficacy of fenestration.

Aortic fenestration has been described as both a reliable $(100 \%$ technical success) and effective technique, with clinical success between $70 \%$ and $93 \%$ at 30 days, ${ }^{17,20}$ versus $60 \%$ for surgery. ${ }^{22}$ This series additionally shows that $\mathrm{AF}$ using the funnel technique is effective $(89 \%$ clinical success). With balloon angioplasty AF, the 30-day mortality rate was $17 \%$ to $25 \%$, with an approximately $20 \%$ complication rate. ${ }^{19,20,25}$ The scissor technique has shown $30 \%$ mortality at 30 days, with roughly $10 \%$ complications. ${ }^{17}$ Mortality in our series was much lower $(7 \%)$, and the morbidity rate was equivalent $(18 \%)$.

Patients with severe ischemia account for $14 \%$ to $26 \%$, with a $33 \%$ to $66 \%$ mortality rate. ${ }^{17,20,27}$ In our series, the severe ischemia rate was higher, at $29 \%$, with a lower mortality rate $(25 \%)$. The mortality rate with the funnel technique, therefore, does not stem from the population presenting globally less-severe MPS, but probably from a more effective reapplication of pressure in the true lumen. 

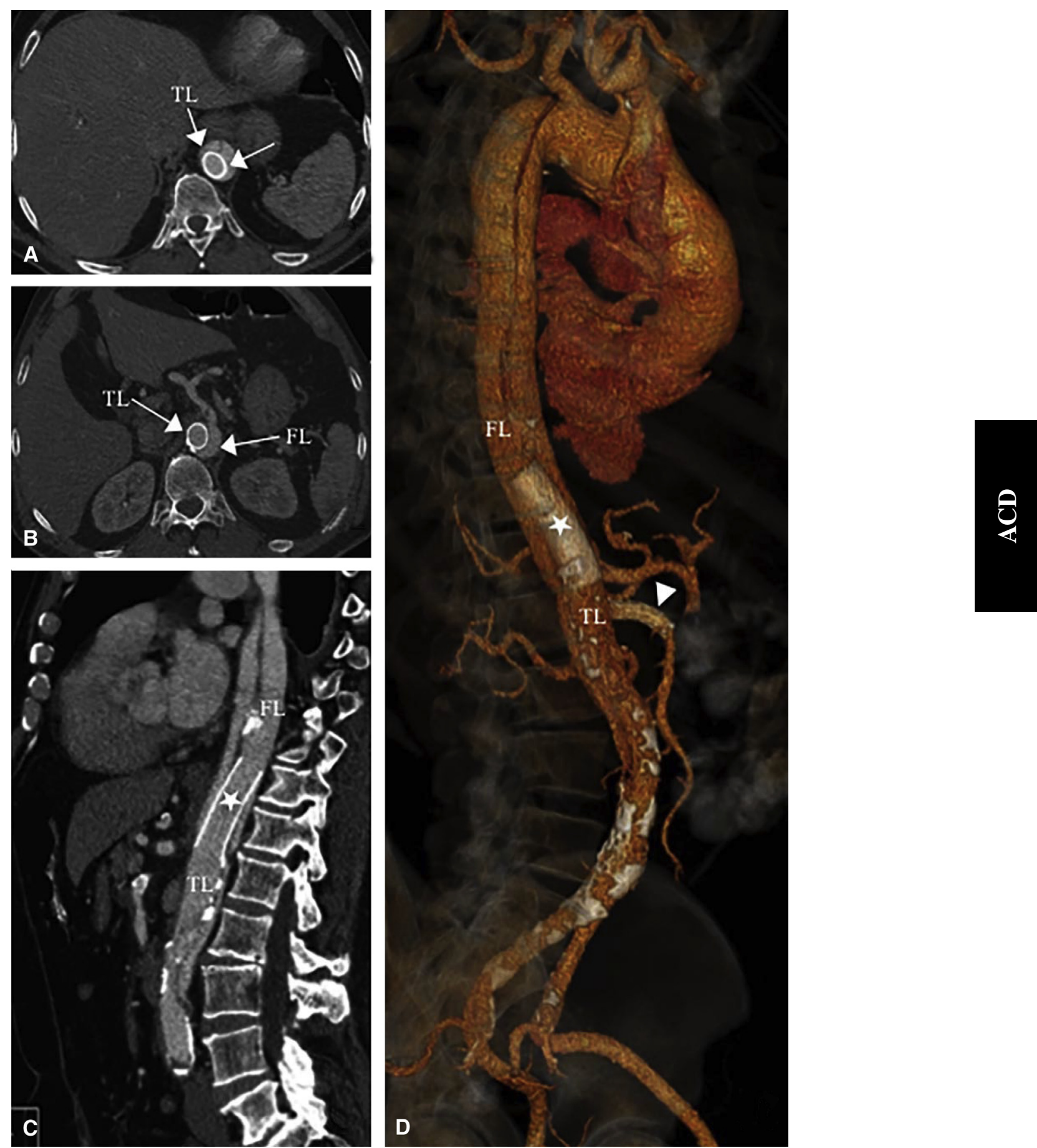

FIGURE 4. Follow-up CT at day 2 in the same patient in (A, B) axial views, (C) sagittal reformations, and (D) VRT reformations showing the stent graft (star) within the TL and the FL, and the good patency of the aortic branches. Another stent has been placed in the superior mesenteric artery in the same procedure because of static compression (arrowhead). Ischemic symptoms disappeared after the procedure, and the patient evolved favorably. $T L$, True lumen; $F L$, false lumen.

This led to the disappearance of the clinical symptoms and the reversion of the acute ischemic lesions, preventing the onset of multiorgan failure. In the present study, only 2 patients $(7 \%)$ died of multiorgan failure, despite the $\mathrm{AF}$, whereas this unfavorable outcome seems more frequent in the other series $(15 \%-25 \%) .{ }^{17,20}$

We did not observe stent malposition or stent migration during grafting, nor injury of the aortic wall or stent 
TABLE 2. Population characteristics

\begin{tabular}{lc}
\hline \multicolumn{1}{c}{ Characteristic } & Value \\
\hline Gender & \\
Male & 9 \\
Female & 19 \\
Median age (range; y) & 56 (47-63) \\
Type A dissection & 19 \\
Type B dissection & 9 \\
Ischemic areas & \\
3 sites & \\
$\quad$ Renal/mesenteric/lower-limb & 4 \\
2 sites & 10 \\
$\quad$ Renal/mesenteric & 5 \\
Renal/lower-limb & 3 \\
$\quad$ Mesenteric/lower-limb & 2 \\
1 site & 14 \\
Renal & 5 \\
Mesenteric & 5 \\
$\quad$ Lower-limb & 4 \\
\hline Values are n, unless otherwise indicated.
\end{tabular}

thrombosis in the long term. Two fractures of stents were discovered inadvertently, both asymptomatic and involving nitinol stents (Memotherm Bard Angiomed, Wachhausstrasse, Germany). We have since decided to use only steel self-expandable Wallstents (Boston Scientific, Natick, Mass), with no new complications discovered to date. No collapse of the stent had been observed, probably owing to the placement of the stent between the 2 lumens, which decreased pressure in the false lumen. Massman and colleagues ${ }^{28}$ have described this type of complication in 4 of 14 patients treated by an uncovered aortic stent graft in the true lumen: This collapse could be a result of the persistent pressure in the false lumen, which allowed the compression of the true lumen and the dilatation of the false lumen over the long term.

Three patients underwent an additional fenestration because the first was deemed insufficient. In these patients, an 18-mm diameter stent was selected for a mean $30-\mathrm{mm}$ diameter aorta in the fenestration area. Finally, this stent diameter was considered too small for the size of the false lumen. Since that time, we have used stents with a larger diameter so that the re-entry orifice in the true lumen is at least two thirds of the total diameter of the aorta, thus ensuring that flow is $>50 \%$

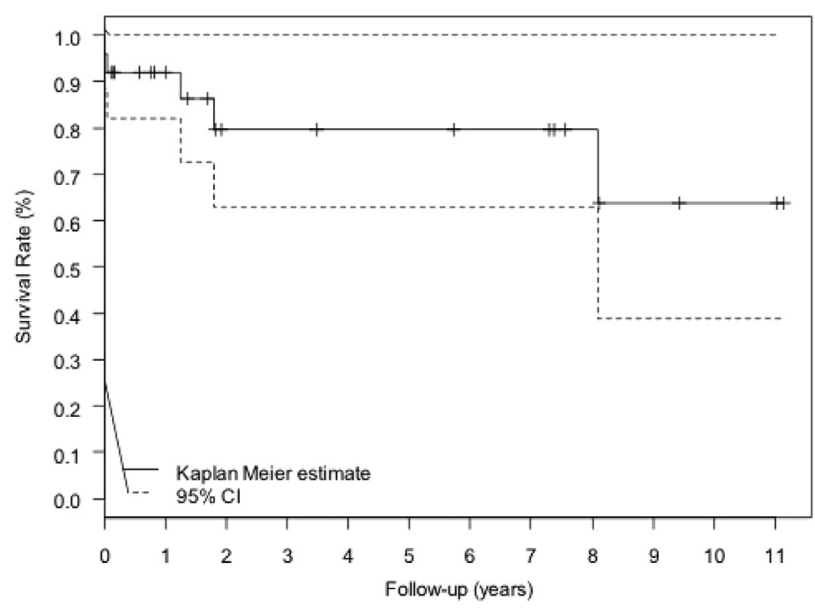

FIGURE 5. Survival rate after treatment by the funnel technique. CI, Confidence interval.

between the true and the false lumen. This is now always possible, however, because the maximal diameter of a Wallstent is $24 \mathrm{~mm}$.

Over the long term, decreased pressure in the false lumen seems to protect against the aneurysmal aortic evolution; $91 \%$ of our patients ( 15 type A and 6 type B) presented a stable aortic diameter. The only factor involved in the growth aortic diameter was the follow up-time, with a mean progression of $1.46 \mathrm{~mm} / \mathrm{year}$, which we considered to be a natural evolution. As reported in the literature, the natural progression of $\mathrm{AD}$ is characterized by dilatation of the descending thoracic aorta in $20 \%$ to $50 \%$ of cases, ${ }^{29}$ and up to $83 \%$ in the segment-by-segment study of the aorta. $^{30,31}$ These findings confirm the hypothesis that blood pressure is reduced within the false lumen upon reapplication of pressure in the true lumen, thus avoiding progression toward aneurysm. Midulla et al. ${ }^{17}$ have reported the same observation.

The small number of patients treated was the main limitation of this study. Further studies, as comparable as possible, and multicentric, are necessary to confirm the efficacy and safety of this new procedure. Another limitation was a recruitment bias concerning bowel ischemia. Some patients were not treated with use of the funnel technique because of the seriousness of their symptoms or the onset of death before treatment.

TABLE 3. Treatment and evolution of patients with severe ischemia

\begin{tabular}{|c|c|c|c|c|c|c|c|}
\hline Severe ischemia sites & $\mathbf{n}$ & Bowel resection & Bowel monitoring & Dialysis & Major complications & Death & Alive \\
\hline Renal/bowel/lower limbs & 2 & 1 & & 2 & & 1 & 1 \\
\hline Renal/bowel & 2 & 1 & & 2 & & 1 & 1 \\
\hline Renal & 1 & & & 1 & & & 1 \\
\hline Bowel & 2 & 1 & 1 & & & & 2 \\
\hline Lower limbs & 1 & & & & 1 & & 1 \\
\hline
\end{tabular}

Values are n, number of patients. 


\section{CONCLUSIONS}

Aortic fenestration by the funnel technique, in patients with MPS during aortic dissection, is an effective treatment (clinical success: 89\%) associated with low morbidity (30day mortality: $7 \%$; major complications: $3.6 \%$ ). Over the long term, no ischemic recurrence was observed, and decreasing the applied pressure of the false lumen seems to be protective against an increase in aortic thoracic diameter. The hemodynamic efficiency of this technique may account for a lower mortality in our series, but this result needs confirmation.

\section{Conflict of Interest Statement}

Authors have nothing to disclose with regard to commercial support.

\section{References}

1. Golledge J, Eagle KA. Acute aortic dissection. Lancet. 2008;372:55-66.

2. Asfoura JY, Vidt DG. Acute aortic dissection. Chest. 1991;99:724-9.

3. Mészáros I, Mórocz J, Szlávi J, Schmidt J, Tornóci L, Nagy L, et al. Epidemiology and clinicopathology of aortic dissection. Chest. 2000;117:1271-8.

4. Daily PO, Trueblood HW, Stinson EB, Wuerflein RD, Shumway NE. Management of acute aortic dissections. Ann Thorac Surg. 1970;10:237-47.

5. Debakey ME, Henly WS, Cooley DA, Morris GC Jr, Crawford ES, Beall AC Jr. Surgical management of dissecting aneurysms of the aorta. J Thorac Cardiovasc Surg. 1965;49:130-49.

6. Wheat MW, Palmer RF, Bartley TD, Seelman RC. Treatment of dissecting aneurysms of the aorta without surgery. J Thorac Cardiovasc Surg. 1965;50:364-73.

7. Swee W, Dake MD. Endovascular management of thoracic dissections. Circulation. 2008;117:1460-73.

8. Rodiere M, Thony F, Michoud M, Frandon J, Ferretti G. Acute visceral ischaemia, early complication of the aortic syndrome: how to detect and manage it? Presse Med. 2011;40:54-61.

9. Di Eusanio M, Trimarchi S, Patel HJ, Hutchinson S, Suzuki T, Peterson MD, et al. Clinical presentation, management, and short-term outcome of patients with type A acute dissection complicated by mesenteric malperfusion: observations from the International Registry of Acute Aortic Dissection. J Thorac Cardiovasc Surg. 2013;145:385-90.

10. Cambria RP, Brewster DC, Gertler J, Moncure AC, Gusberg R, Tilson MD, et al. Vascular complications associated with spontaneous aortic dissection. J Vasc Surg. 1988;7:199-209.

11. Jonker FH, Patel HJ, Upchurch GR, Williams DM, Montgomery DG, Gleason TG, et al. Acute type B aortic dissection complicated by visceral ischemia. J Thorac Cardiovasc Surg. 2015;149:1081-6.

12. Williams DM, Lee DY, Hamilton BH, Marx MV, Narasimham DL, Kazanjian SN, et al. The dissected aorta: part III. Anatomy and radiologic diagnosis of branch-vessel compromise. Radiology. 1997;203:37-44.

13. Nienaber CA, Fattori R, Lund G, Dieckmann C, Wolf W, Von Kodolitsch Y, et al. Nonsurgical reconstruction of thoracic aortic dissection by stent-graft placement. N Engl J Med. 1999;340:1539-45.

14. Dake MD, Kato N, Mitchell RS, Semba CP, Razavi MK, Shimono T, et al. Endovascular stent-graft placement for the treatment of acute aortic dissection. $N$ Engl J Med. 1999;340:1546-52.

15. Nienaber CA, Zannetti S, Barbieri B, Kirsche S, Scharek W, Rehders TC, et al. INvestigation of STEnt grafts in patients with type B Aortic Dissection: design of the INSTEAD trial—a prospective, multicenter, European randomized trial. Am Heart J. 2005;149:592-9.

16. Botsios S, Schuermann K, Maatz W, Keck N, Walterbusch G. Complicated acute type B dissections: a single-center experience with endovascular treatment Thorac Cardiovasc Surg. 2010;58:280-4.

17. Midulla M, Renaud A, Martinelli T, Koussa M, Mounier-Vehier C, Prat A, et al. Endovascular fenestration in aortic dissection with acute malperfusion syndrome: immediate and late follow-up. J Thorac Cardiovasc Surg. 2011;142: $66-72$.

18. Beregi JP, Haulon S, Otal P, Thony F, Bartoli JM, Crochet D, et al. Endovascular treatment of acute complications associated with aortic dissection: midterm results from a multicenter study. J Endovasc Ther. 2003;10:486-93.

19. Patel HJ, Williams DM, Meerkov M, Dasika NL, Upchurch GR Jr, Deeb GM Long-term results of percutaneous management of malperfusion in acute type B aortic dissection: implications for thoracic aortic endovascular repair. J Thorac Cardiovasc Surg. 2009;138:300-8.

20. Slonim SM, Miller DC, Mitchell RS, Semba CP, Razavi MK, Dake MD. Percutaneous balloon fenestration and stenting for life-threatening ischemic complications in patients with acute aortic dissection. J Thorac Cardiovasc Surg. 1999; 117:1118-26.

21. Bellomo R, Ronco C, Kellum JA, Mehta RL, Palevsky P, Acute Dialysis Quality Initiative workgroup. Acute renal failure-definition, outcome measures, animal models, fluid therapy and information technology needs: the Second International Consensus Conference of the Acute Dialysis Quality Initiative (ADQI) Group. Crit Care. 2004;8:R204-12.

22. Fattori R, Tsai TT, Myrmel T, Cooper JV, Trimarchi S, Li J, et al. Complicated acute type B dissection: Is surgery still the best option?: a report from the International Registry of Acute Aortic Dissection. JACC Cardiovasc Interv. 2008;1 395-402.

23. Nienaber CA, Rousseau H, Eggebrecht H, Kische S, Fattori R, Rehders TC, et al Randomized comparison of strategies for type B aortic dissection: the INvestigation of STEnt Grafts in Aortic Dissection (INSTEAD) trial. Circulation. 2009; 120:2519-28.

24. Kos S, Gürke L, Jacob AL. A novel fenestration technique for abdominal aortic dissection membranes using a combination of a needle re-entry catheter and the "cheese-wire" technique. Cardiovasc Intervent Radiol. 2011;34:1296-302.

25. Chavan A, Hausmann D, Dresler C, Rosenthal H, Jaeger K, Haverich A, et al. Intravascular ultrasound-guided percutaneous fenestration of the intimal flap in the dissected aorta. Circulation. 1997;96:2124-7.

26. Beregi JP, Prat A, Gaxotte V, Delomez M, McFadden EP. Endovascular treatment for dissection of the descending aorta. Lancet. 2000;356:482-3.

27. O’Donnell S, Geotchues A, Beavers F, Akbari C, Lowery R, Elmassry S, et al Endovascular management of acute aortic dissections. J Vasc Surg. 2011;54 1283-9.

28. Massmann A, Kunihara T, Fries P, Schneider G, Buecker A, Schäfers HJ. Uncovered stent implantation in complicated acute aortic dissection type B. J Thorac Cardiovasc Surg. 2014;148:3003-11.

29. Trimarchi S, Jonker FHW, van Bogerijen GHW, Tolenaar JL, Moll FL, Czerny M, et al. Predicting aortic enlargement in type B aortic dissection. Ann Cardiothorac Surg. 2014;3:285-91.

30. Tolenaar JL, van Keulen JW, Jonker FH, van Herwaarden JA, Verhagen HJ, Moll FL, et al. Morphologic predictors of aortic dilatation in type B aortic dissection. J Vasc Surg. 2013;58:1220-5.

31. Sueyoshi E, Sakamoto I, Hayashi K, Yamaguchi T, Imada T. Growth rate of aortic diameter in patients with type B aortic dissection during the chronic phase. Circulation. 2004;110(11 Suppl 1):II256-61.

Key Words: aortic dissection, aortic fenestration, stent, malperfusion 